Supplement of Geosci. Model Dev., 8, 2749-2776, 2015

http://www.geosci-model-dev.net/8/2749/2015/

doi:10.5194/gmd-8-2749-2015-supplement

(C) Author(s) 2015. CC Attribution 3.0 License.

(c) (i)

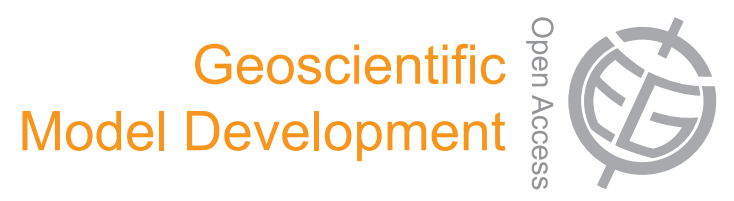

Supplement of

\title{
A new chemistry option in WRF-Chem v. 3.4 for the simulation of direct and indirect aerosol effects using VBS: evaluation against IMPACT-EUCAARI data
}

P. Tuccella et al.

Correspondence to: P. Tuccella (paolo.tuccella@aquila.infn.it)

The copyright of individual parts of the supplement might differ from the CC-BY 3.0 licence. 
Table S1. ATR-42 flight during the EUCAARI campaign from 14 to 31 May 2008. In the Table are reported the date of the flight, flight number and take-off and landing time.

\begin{tabular}{ccc}
\hline Date & RF number & $\begin{array}{c}\text { Take-off and } \\
\text { landing time(UCT) }\end{array}$ \\
$14-05-2008$ & 50 & $12: 13-15: 05$ \\
$15-05-2008$ & 51 & $06: 19-09: 50$ \\
$15-05-2008$ & 52 & $11: 49-15: 06$ \\
$18-05-2008$ & 53 & $08: 50-11.10$ \\
$18-05-2008$ & 54 & $12: 01-14: 45$ \\
$19-05-2008$ & 55 & $11: 06-14: 24$ \\
$20-05-2008$ & 56 & $09: 02-11: 06$ \\
$21-05-2008$ & 57 & $10: 07-12: 06$ \\
$21-05-2008$ & 58 & $13: 45-15: 14$ \\
$26-05-2008$ & 59 & $11: 59-15: 20$ \\
$28-05-2008$ & 60 & $07: 54-09: 55$ \\
$28-05-2008$ & 61 & $13: 24-15: 40$ \\
$29-05-2008$ & 62 & $13: 15-14: 36$ \\
$30-05-2008$ & $56-14: 42$ \\
\hline
\end{tabular}





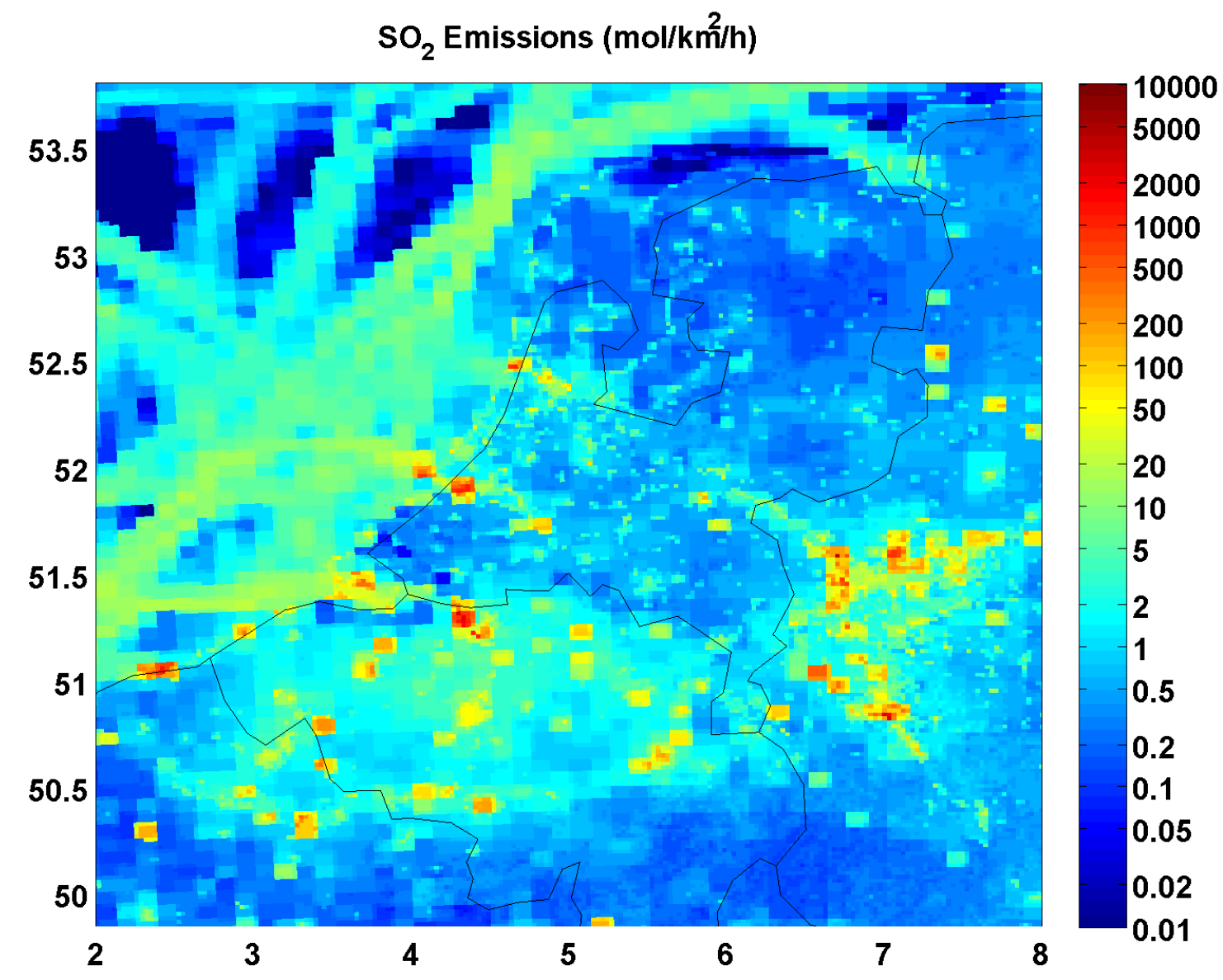

Figure S1. Diurnal average of weekday $\mathrm{SO}_{2}$ emissions used in the model in domain D3. 

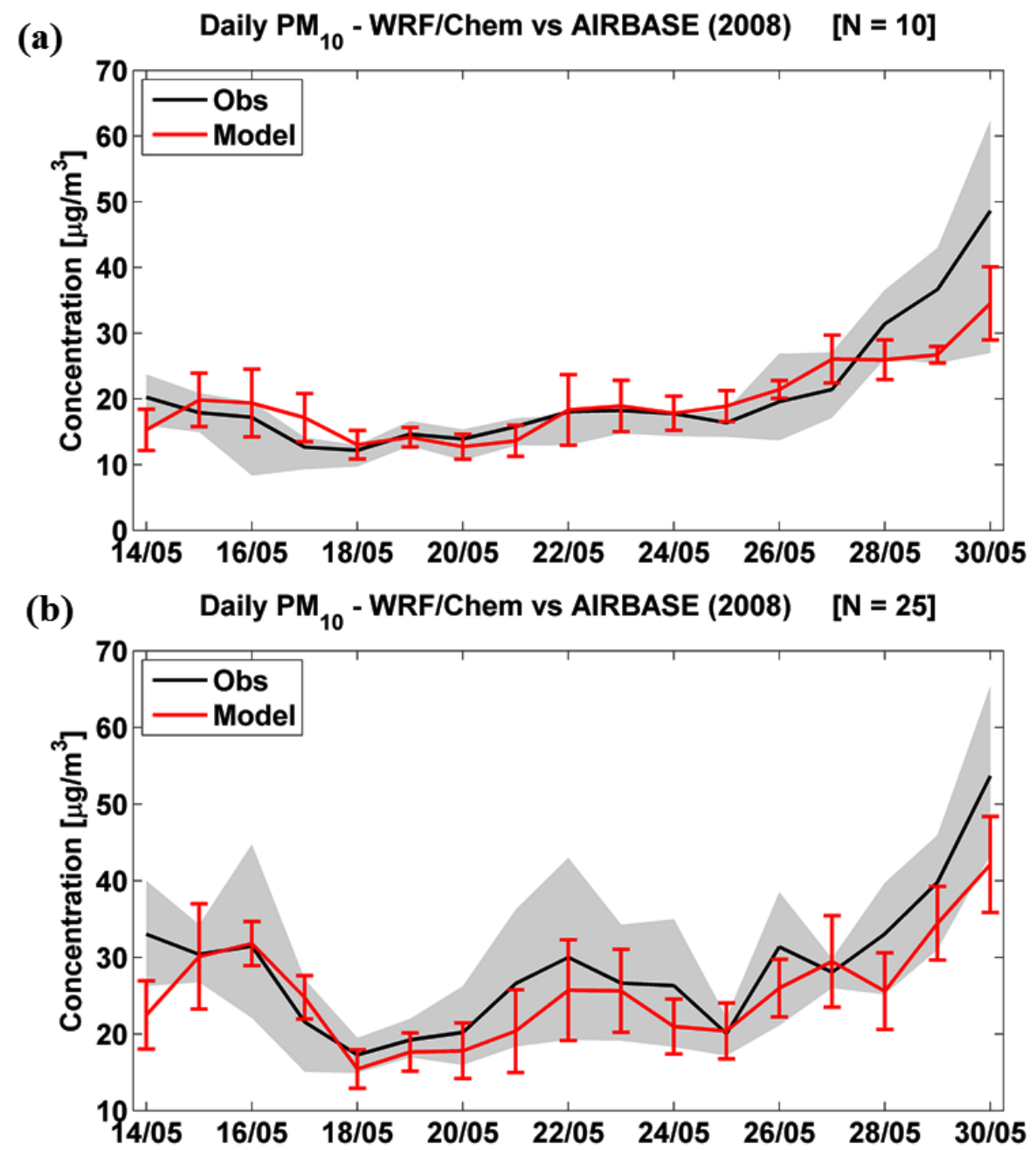

(c)

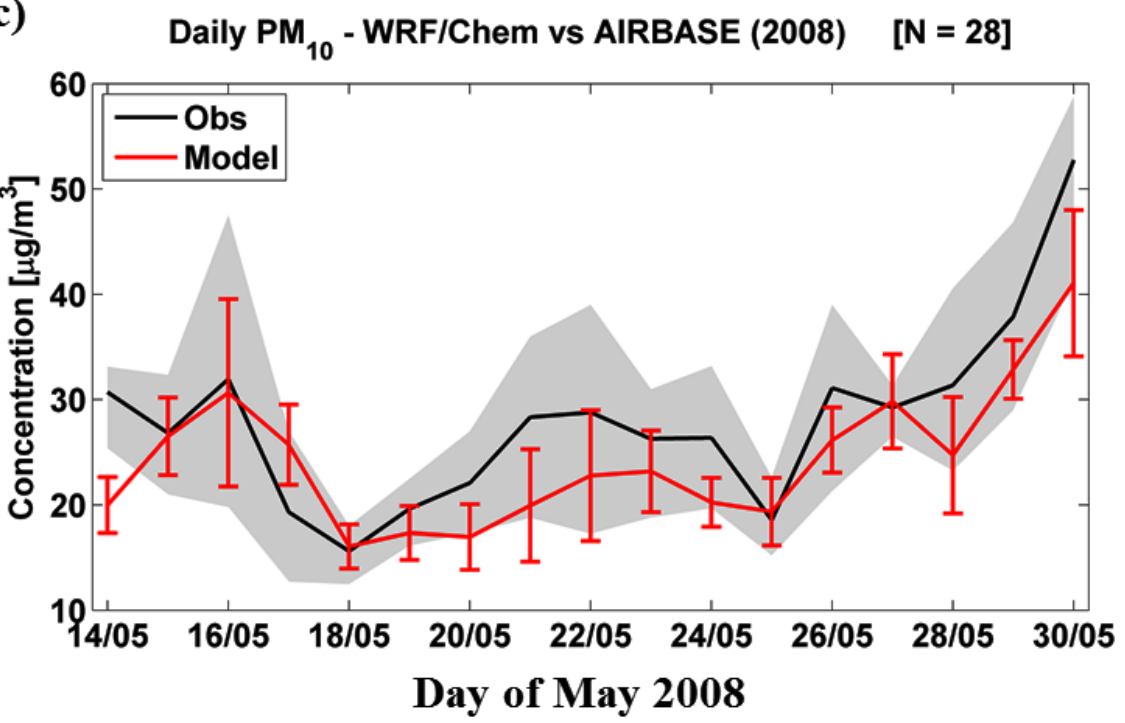

Figure S2. Comparison of $\mathbf{P M}_{10}$ daily observations (black) at rural (a), suburban (b), and urban (c) AIRBASE stations with WRF/Chem simulations (red). Values are averaged over all available stations. Mean (solid line) and 25th and 75th percentiles of time series are shown (red bars and shaded area). 


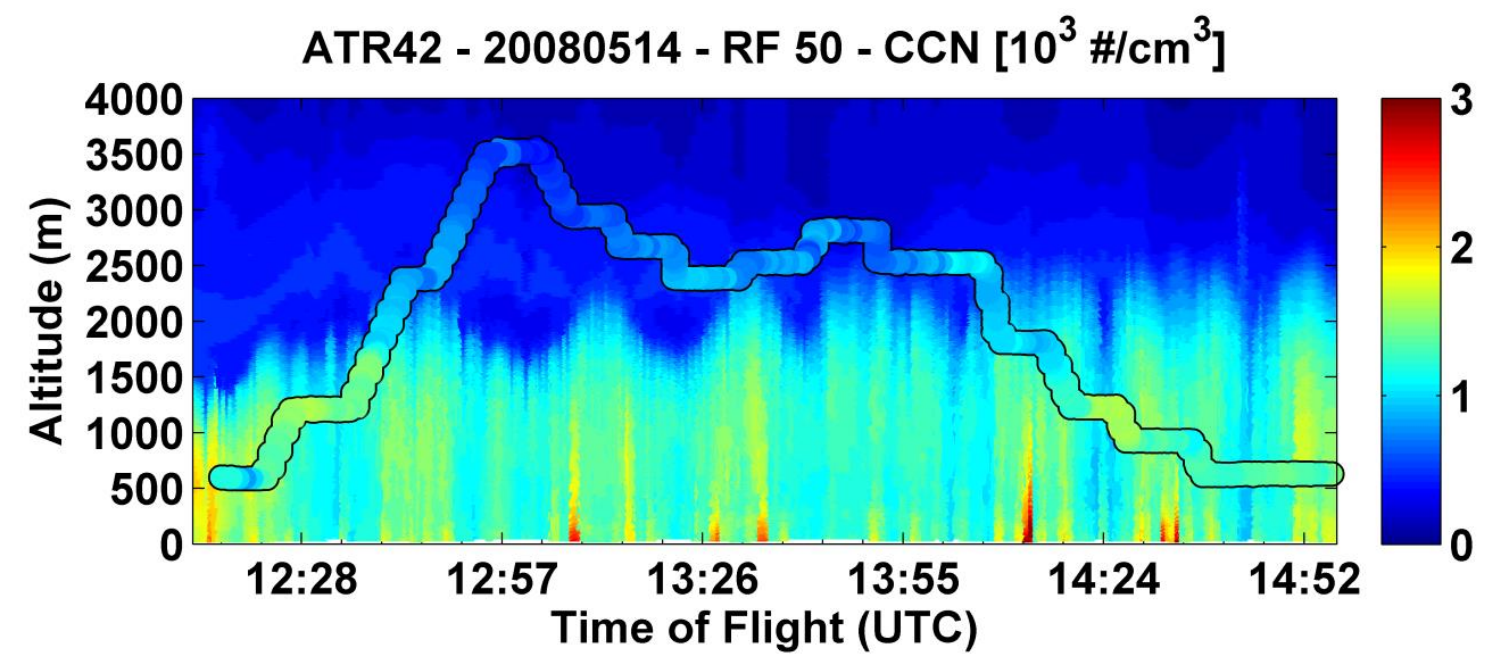

Figure S3. As Figure 8 of the main text, but for CCN. 

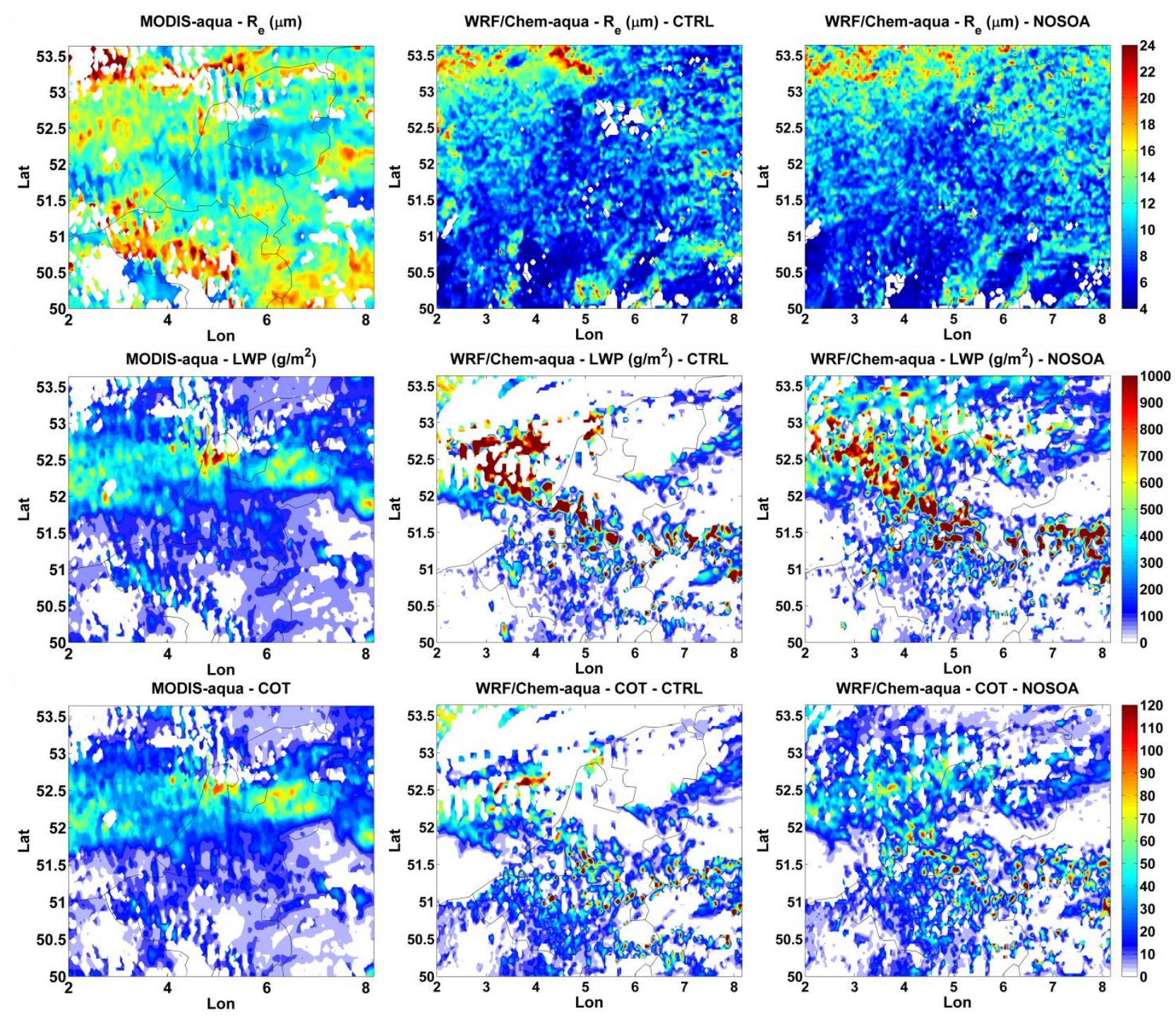

Figure S4. As Figure 12 of the main text, but for 25-27 May 2008 averages. 

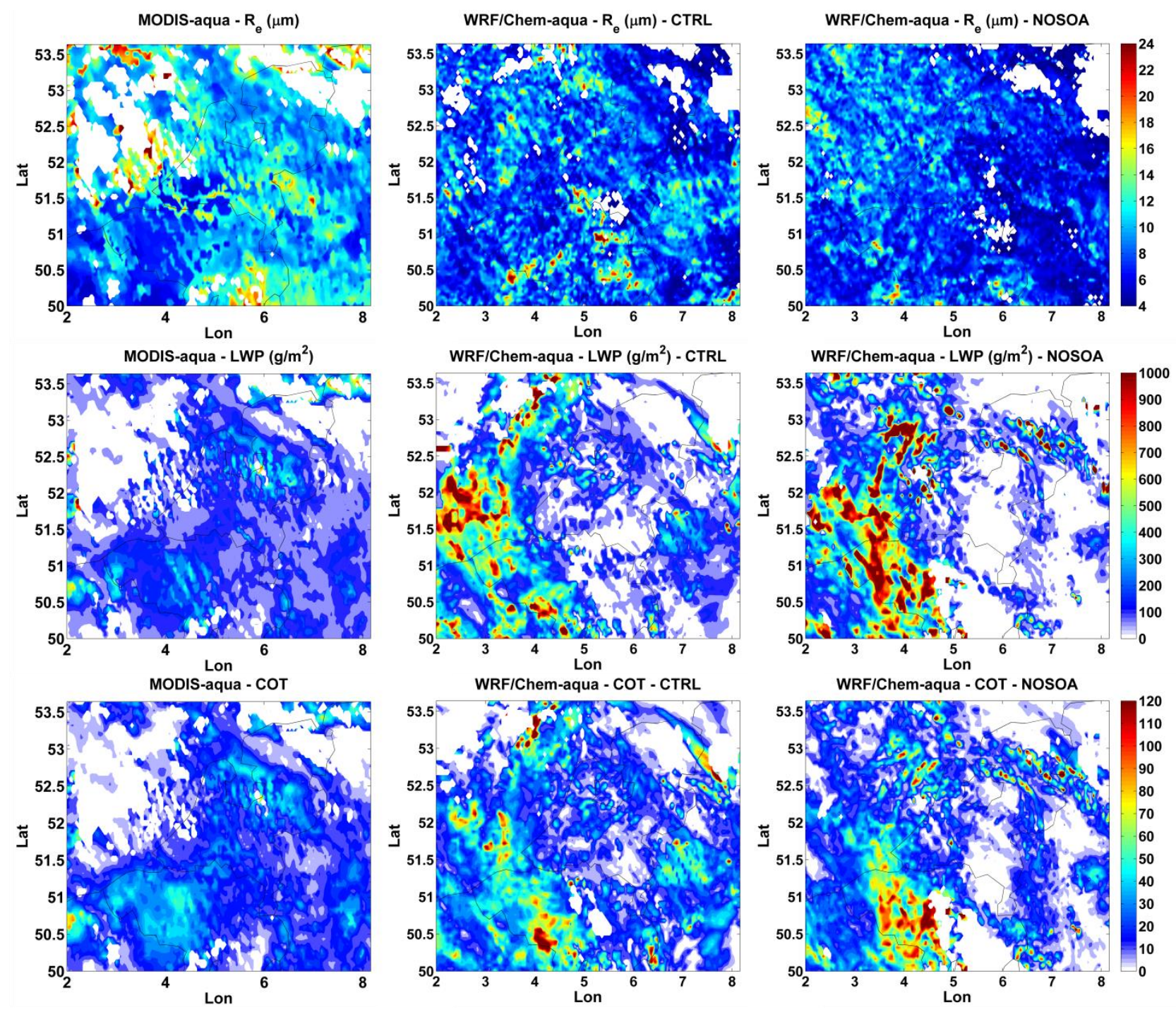

Figure S5. As Figure 12 of the main text, but for 28-30 May 2008 averages. 

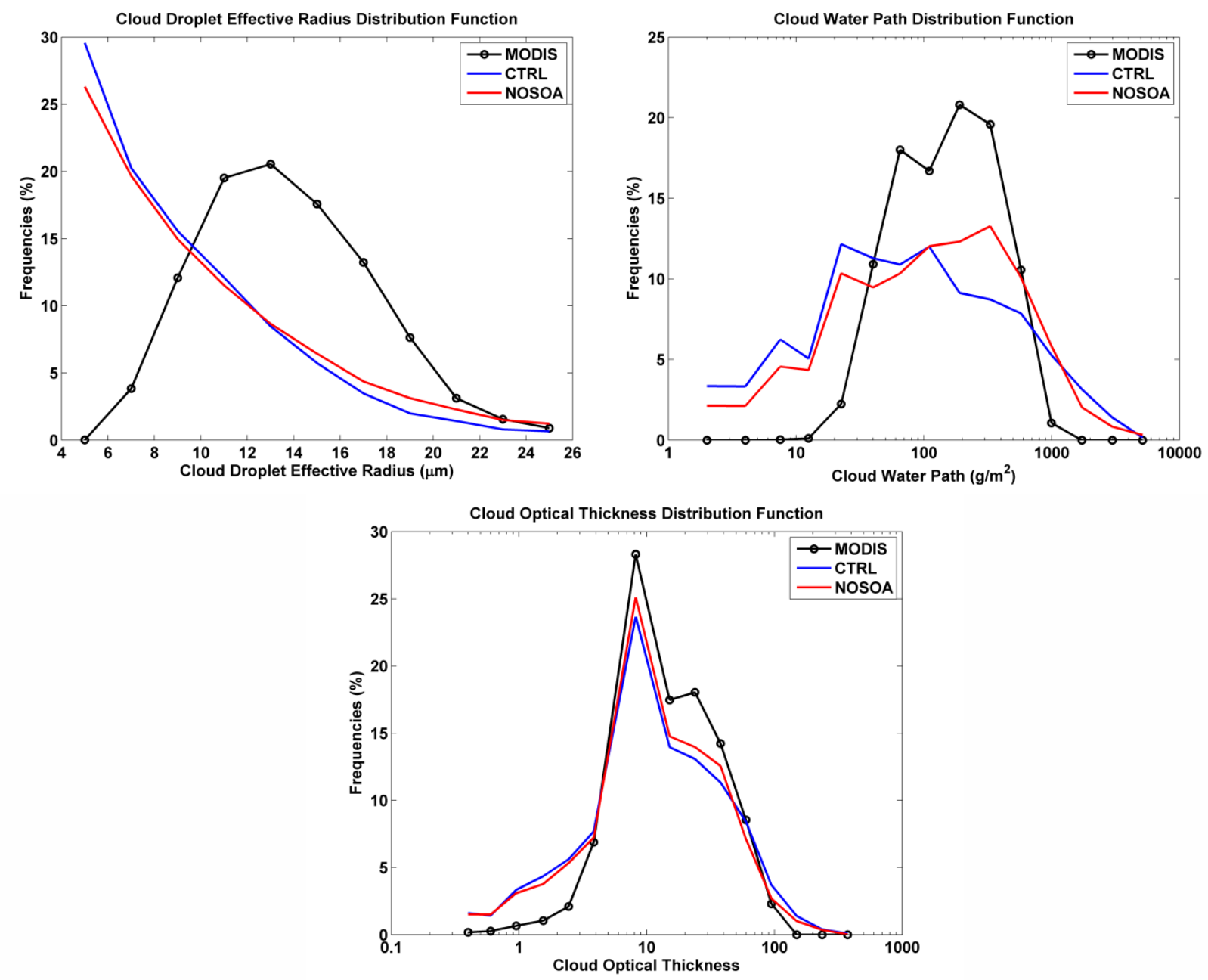

Figure S6. As Figure 13 of the main text, but for 25-27 May 2008 averages. 

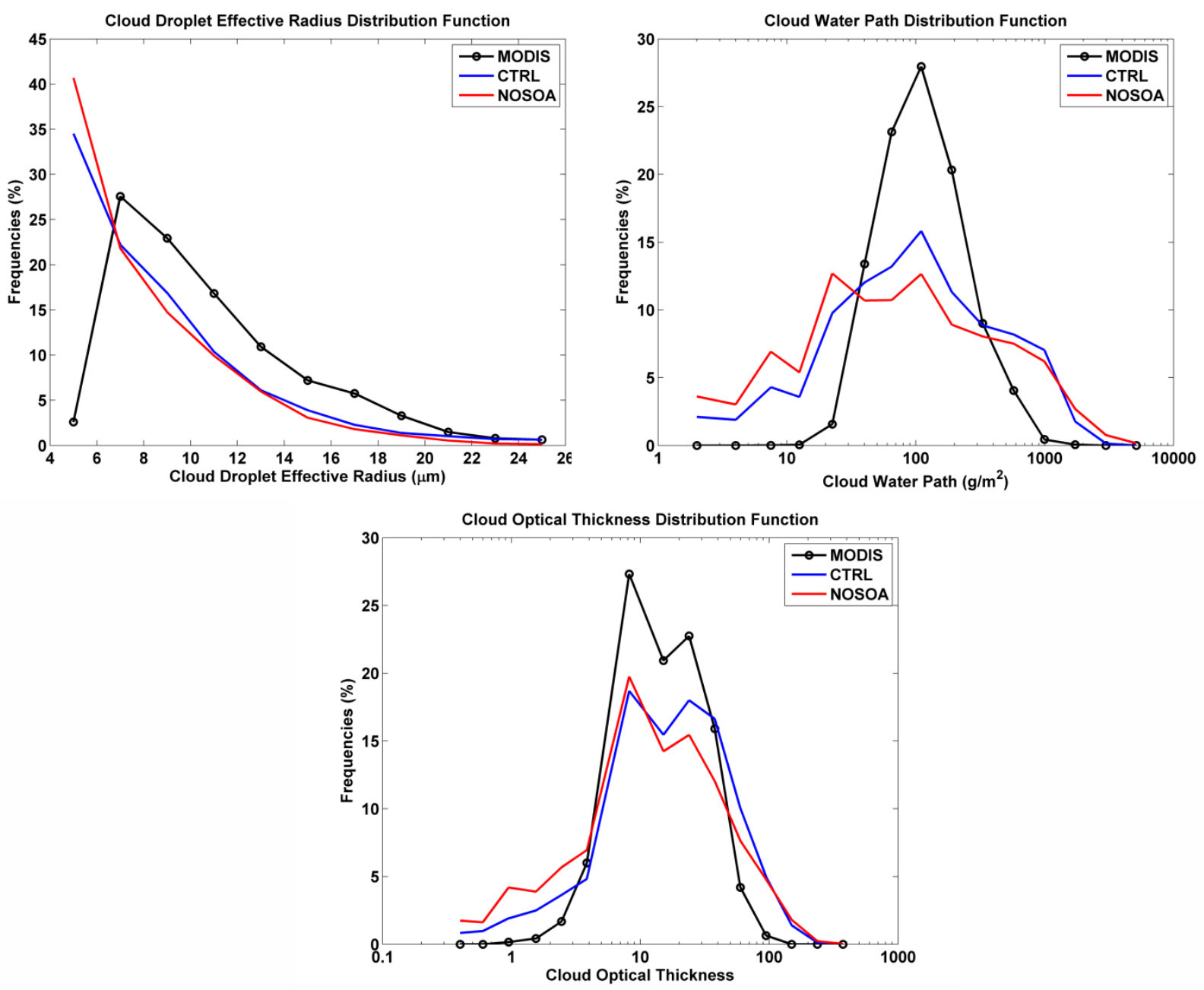

Figure S7. As Figure 13 of the main text, but for 28-30 May 2008 averages. 

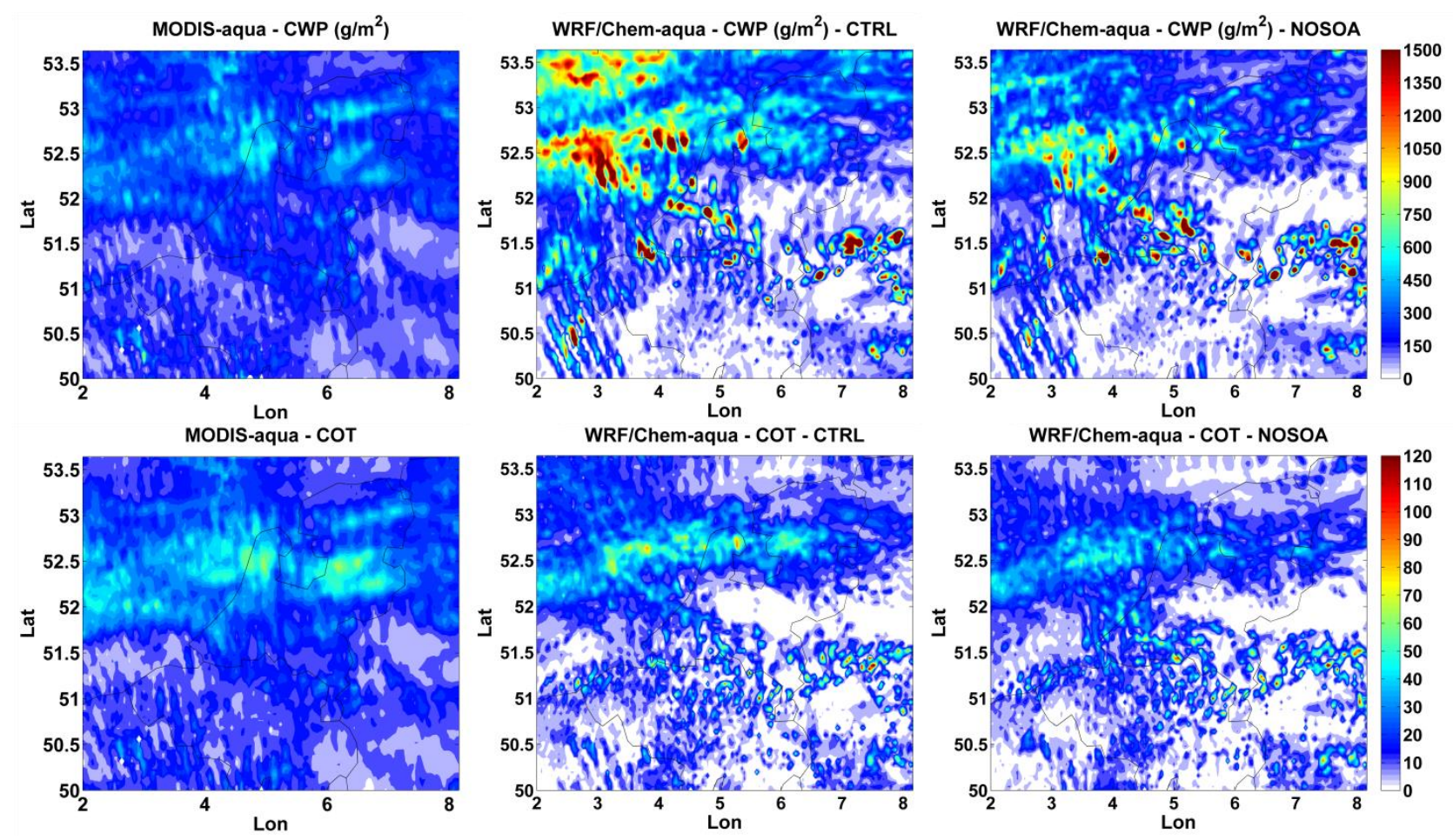

Figure S8. As Figure 14 of the main text, but for 25-27 May 2008 averages. 

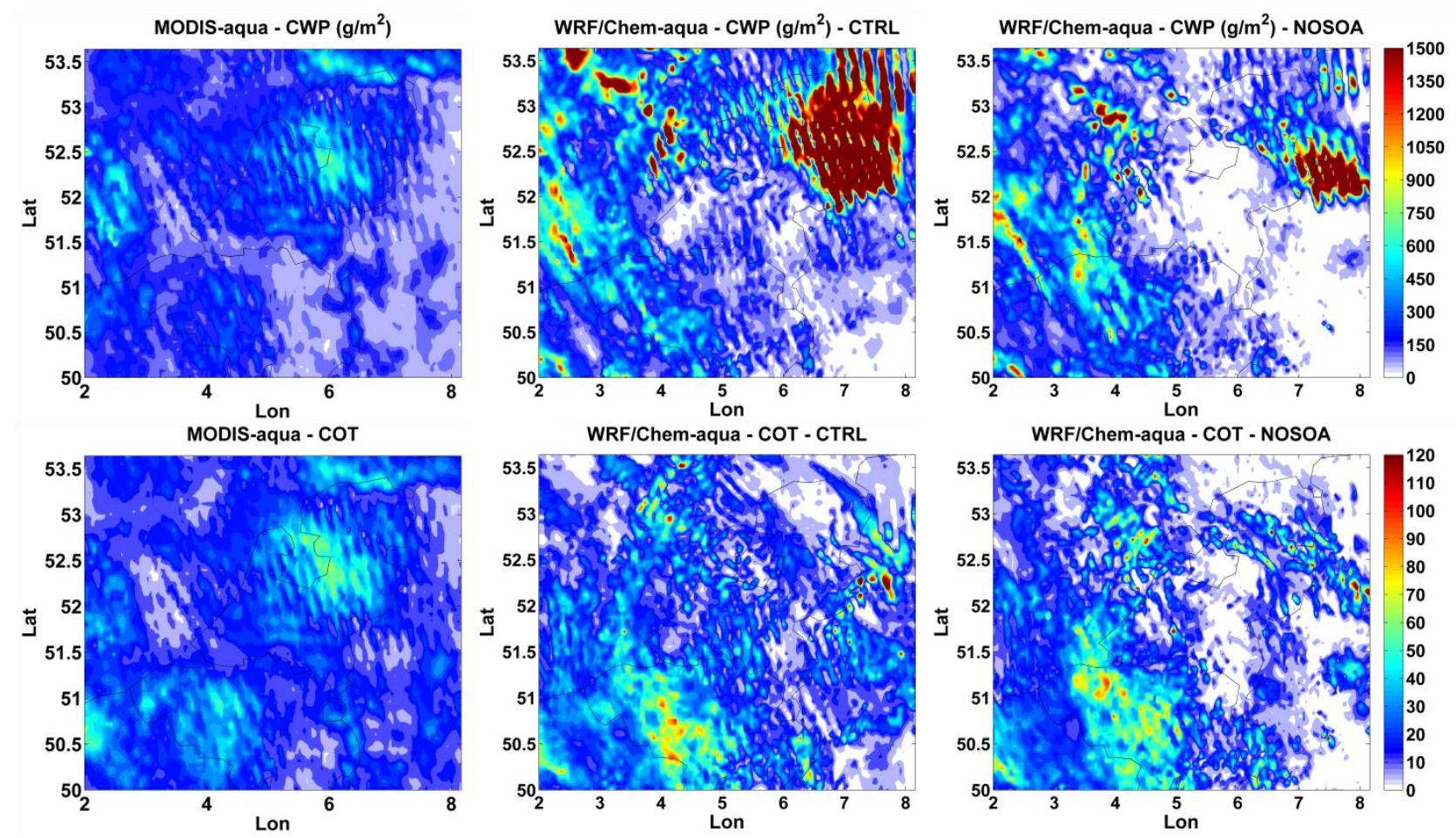

Figure S9. As Figure 14 of the main text, but for 25-30 May 2008 averages. 
a)

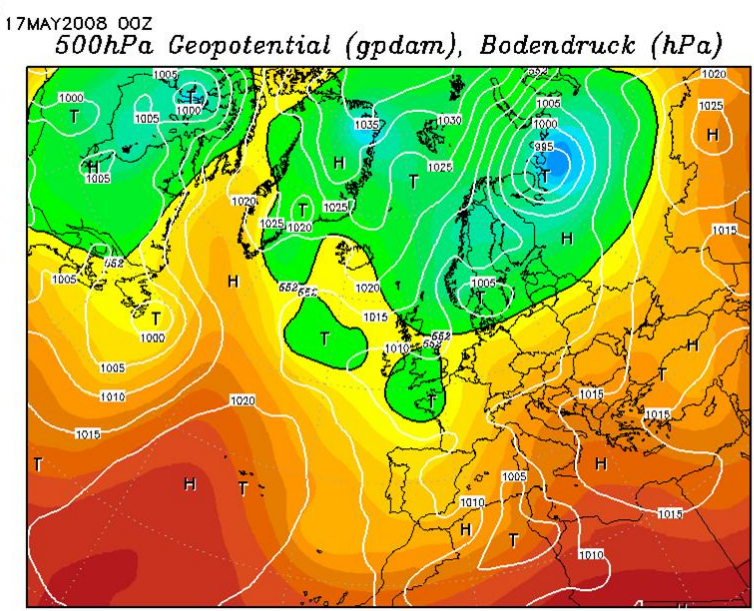

Daten: CF Reennalysis
(c) Wetterzentroles b)

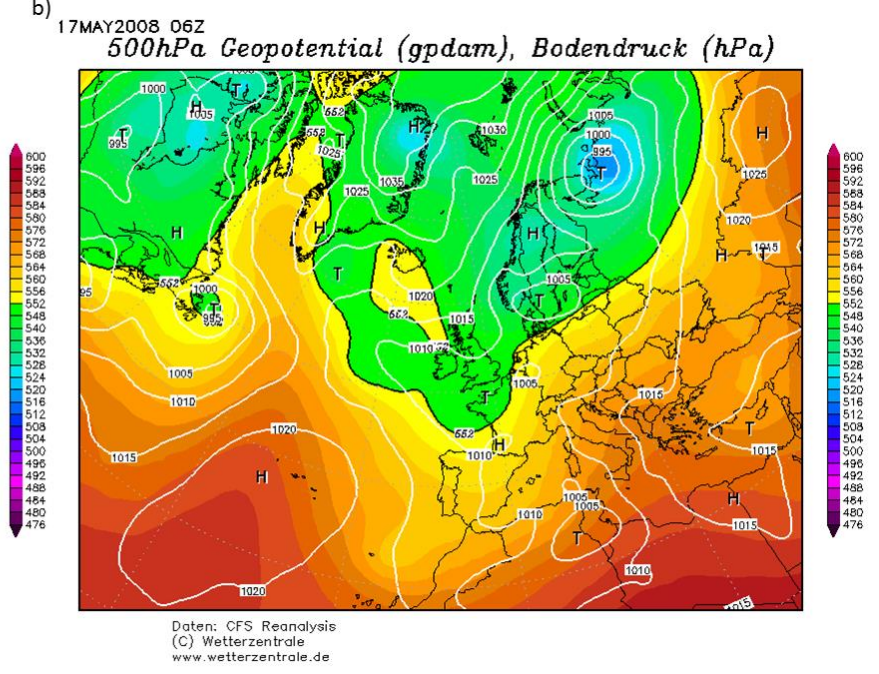

Figure S10. 500 hPa geopotential height (colors) and sea level pressure (white line) from Climate System Forecast reanalysis on 17 May 2008 at 00 (a) and 06 (b) UTC. 


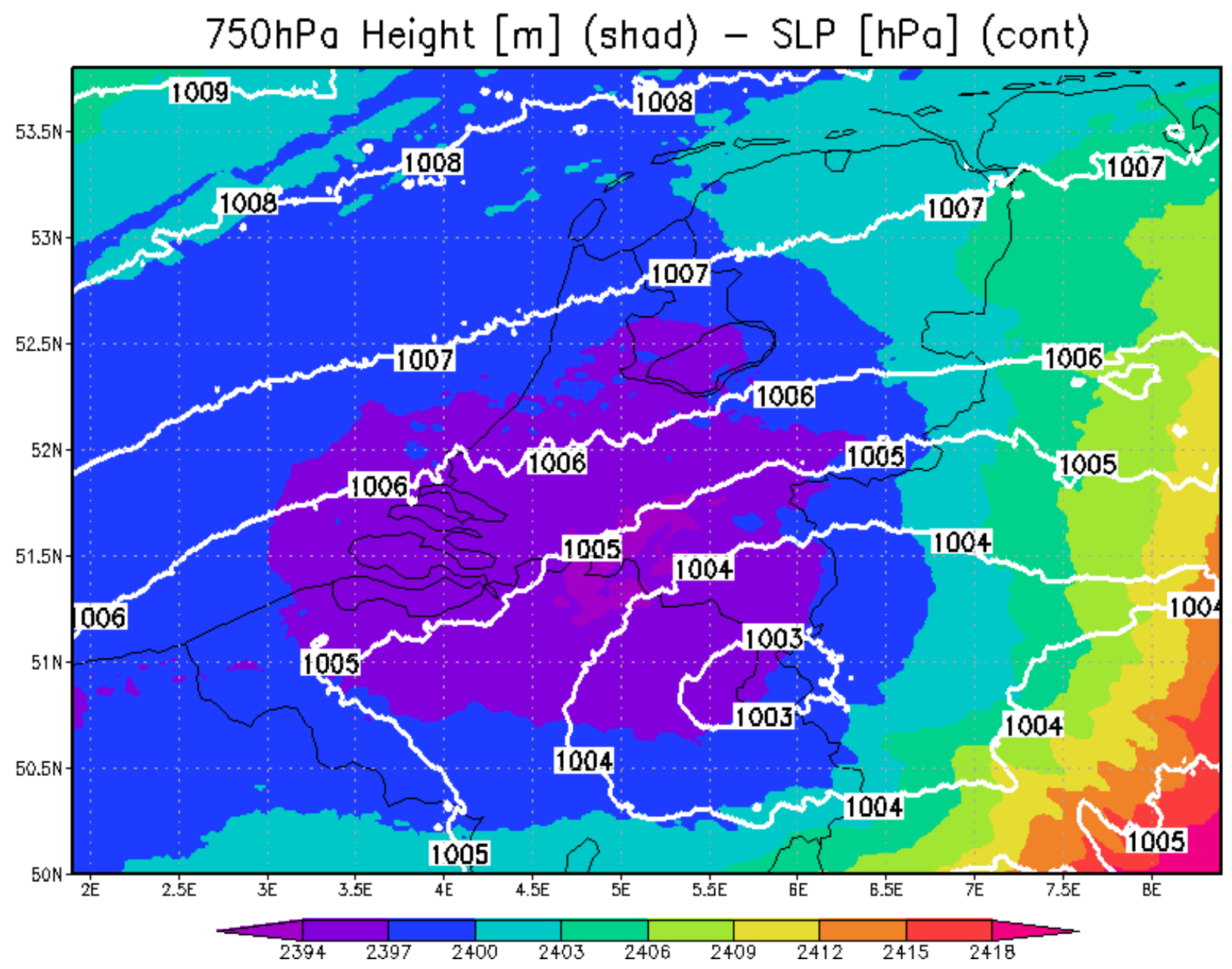

Figure S11. 750 hPa geopotential height (colors) and sea level pressure (white line) simulated by WRF/Chem on 17 May 2008 at 06 UTC. 


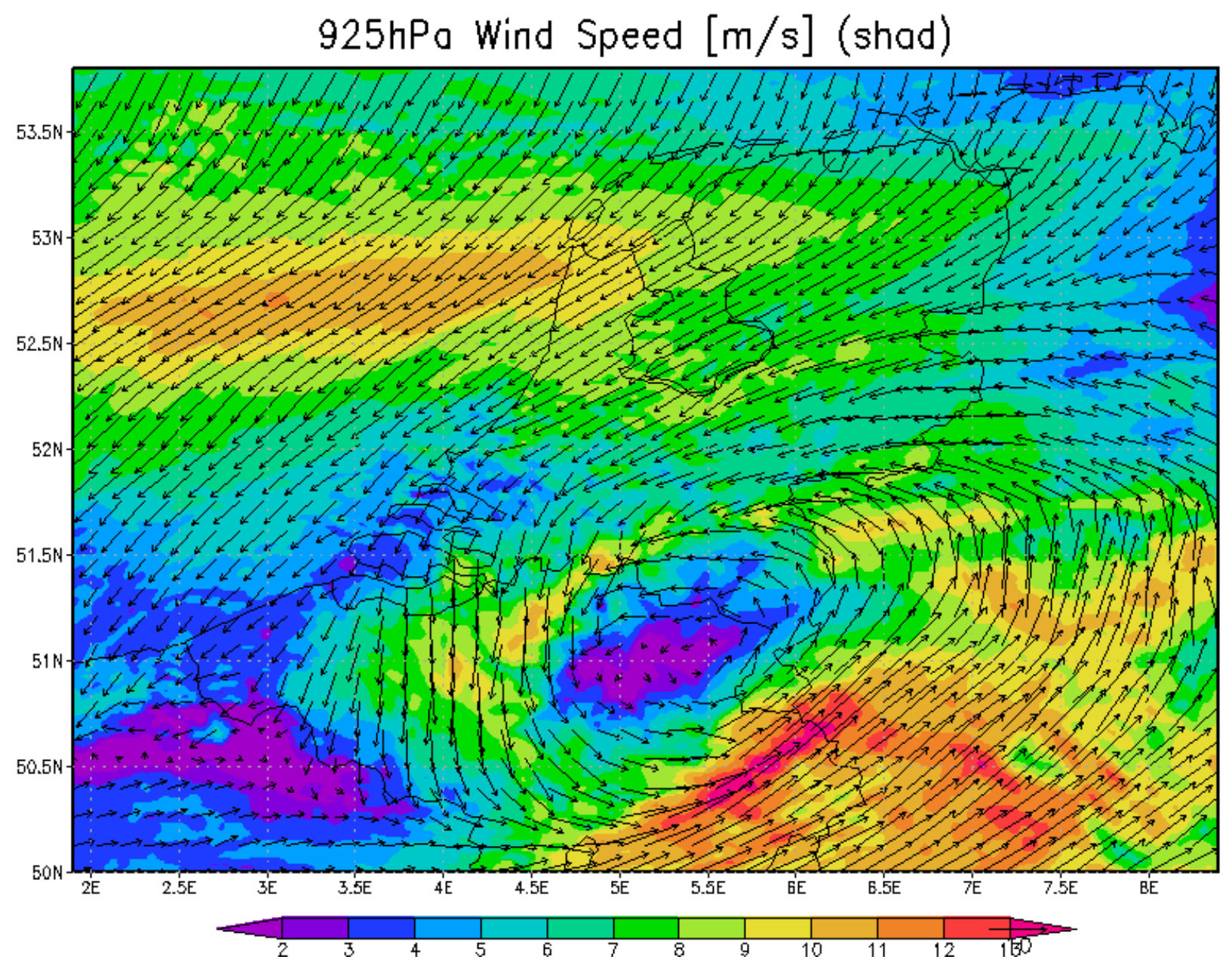

Figure S12. 925 hPa wind speed and direction simulated by WRF/Chem on 17 May 2008 at 06 UTC. 